\title{
Factors influencing the compliance of workplace safety culture in the government linked company (GLC)
}

\author{
Abdul Aziz Mat Isa ${ }^{1 *}$, Warishah Abdul Wahab ${ }^{1}$, Rohayu Che Omar ${ }^{1}$, Mohd Zaid Mohd Nordin ${ }^{2}$, Hairin Taha ${ }^{1}$, Rasyikin \\ Roslan $^{1}$ \\ ${ }^{1}$ Institute of Energy Infrastructure, Universiti Tenaga Nasional,43000 Kajang, Malaysia \\ ${ }^{2}$ College of Graduate Studies, Universiti Tenaga Nasional, Kajang, 43000, Malaysia
}

\begin{abstract}
This research focused on five factors; the management commitments towards safety, availability of safety rules and procedures, safety communication and feedback, the effectiveness of safety training, and the acquisition of safety knowledge that contributes to compliance of safety culture in the government-linked companies (GLC), by exploring various dimensions by which converge into achieving organizational safety performance outcomes. The importance of safety performance in the GLC is to ensure the employees have the right safety culture, a safe working environment, and comply with safety rules and procedures. The contribution of the findings of this study may provide knowledge of existing safety management practices in Malaysia's Government Linked Company (GLC) and facilitate the organizations in evaluating the importance of safety management on their performance. This study also emphasizes the relationship between the five factors mentioned towards the compliance of safety culture in the organization. Besides that, it also provides an empirical review on which components of safety management practices have a better relationship with the organizational safety culture. Based on the results obtained, there is a positive correlation between management commitments towards safety, availability of safety rules and procedures, safety communication and feedback, the effectiveness of safety training, and acquisition of safety knowledge with regards to employees' safety compliance towards a better safety culture in the organization.
\end{abstract}

\section{Introduction}

All accidents occur due to multiple causes. Therefore, it is crucial to identify the causes of accidents so that it can prevent from reoccurring in the future hence minimize the injury, ill-health and also cost to the business. By identifying the factors of the accident at the workplace, it is essential to investigate those that occurred and considering the appropriate preventative measures in reducing the risk of them happening again.

Multiple studies have reported the impact of safety management on a safe environment in the workplace. A review of early research by [1] reveals that management commitment to safety was the primary factor in successful safety programs as well as other factors. More safety staff, safety committees, and safety training contributed to low accident rate companies [2]. They also confirmed that management commitment to safety is essential. Factors such as management involvement, selected promotional efforts, workforce characteristics, and physical conditions played roles in injury frequencies [3]. Safety behaviours and positive outcomes via workers' safety knowledge and motivation were found to have a positive relationship with management commitment [4].

Successful health and safety programs may benefit the company monetarily in several different ways such as reducing down insurance costs, reducing costly litigation and disability claims, increasing the productivity of employees, leading to more contracts as well as reducing the number of compliance inspections and associated penalties. It has been reported that companies not equipped with safety and health programs recorded $30 \%$ more accidents than those with the programs [5]. The problems related to safety are due to inconsistencies in applying operating procedures as well as due to non-existence procedures [6].

Communication is the critical part of promoting safety initiatives among employees- Like most workplace initiatives, effective employee communication and a resulting high engagement with the initiative is key to its success. An earlier study suggests that both management communication and employee feedback are essential for suggesting safety improvements and reporting near misses as well as unsafe conditions and practices [7-9]. It shows that poor communication occurs due to multiple causes for example lack of information or knowledge, goals and priorities are not clearly explaining and failing to ask questions when something is unclear. Preconceived ideas/close-mindedness, jumping to conclusions, not understanding others' needs, losing patience and allowing discussions to become heated, time pressure, failure to explore all options, and poor communication patterns are also part of poor communication. The empathic communication style, which is characterized

* Corresponding author: azan@uniten.edu.my, rohayu@uniten.edu.my 
by compassionate, concerned, and considerate verbal behaviour to prevent poor communication in an organization was proposed by [10]. The effectiveness of safety communication profoundly influences safety culture in an organization. The empathic communication style would improvise safety performance, better morale, and enhanced organizational culture.

Safety training and education are vital in teaching safe attitudes and providing feedback on the effectiveness of current safety procedures. This section measures the level and effectiveness of safety training in terms of developing and sustaining a work environment conducive to incident and injury-free. A study by [11] shows that safety training can change workers' safe behaviour and attitude. Prevention can be carried out successfully when employees understand better about the work's potential hazards and risks.

Safety knowledge is the crucial knowledge that must be practiced to ensure a safe working environment. Health knowledge means information and skills that relate to preserving or maintaining people free of illness, injury $[12,13]$. Failure to utilize this knowledge in dayto-day practice may increase accident probability and may lead to an accident. This knowledge ranges from standard operating procedures, safety barriers, as well as emergency procedures. The knowledge of safety also includes general competencies such as training and understanding everyone's roles and any approved code of practice and guidance.

Practical safety training is a fundamental element in every successful organization. Safety training includes accident prevention programs and any occupational safety and health programs. Training improves employees' knowledge and attitudes [14]. An organization with a favourable climate for safety would provide sufficient training to have productive employees [15]. The knowledge gain from the training may save lives. For instance, in a chemical hazard workplace, a significant accident may occur due to minor errors (human or technical) such as out-of-control chemical reactions. During these situations, good knowledge of the processes, associated dangers, and methods to prevent them are crucial for workers in such plants [14]. Safety culture needs to be a part of organizational culture that is supported by the management and affects workers' attitudes and behaviours to an organization's ongoing safety performance. Based on past research and other relevant items, the independent variable identified are the management commitments towards safety, availability of safety rules and procedures, safety communication and feedback, the effectiveness of safety training, and acquisition of safety knowledge while the dependent variable is the compliance of safety culture in the organization. Thus, the relationships between the five variables are outlined in Figure 1.

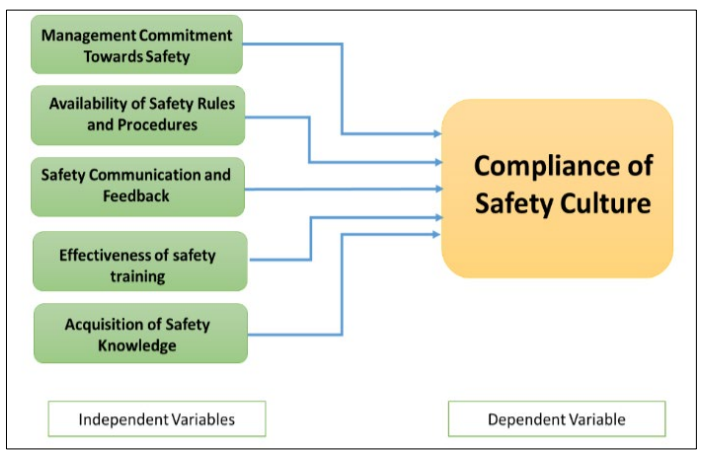

Fig. 1. Theoretical framework.

The specific objectives of the research are to investigate the relationship of the management commitments towards safety, availability of safety rules and procedures, safety communication and feedback, the effectiveness of safety training, and acquisition of safety knowledge towards the compliance of safety culture in Malaysia's government-linked company (GLC). Through literature review gap analysis, there five hypotheses outlined describe as:

i. H1: There is a significant relationship between the management commitment towards safety and compliance of safety culture in the GLC.

ii. H2: There is a significant relationship between the availability of safety rules and procedures and compliance with safety culture in the GLC.

iii. H3: There is a significant relationship between safety communication and feedback and compliance of safety culture in the GLC.

iv. H4: There is a significant relationship between the effectiveness of safety training and compliance of safety culture in the GLC.

v. H5: There is a significant relationship between the acquisition of safety knowledge and compliance with safety culture in the GLC.

\section{Materials and methods}

The methodology of this study is divided into three main steps Quantitative Research Method, Data Collection, and Data Analysis, as shown in Figure 2 below.

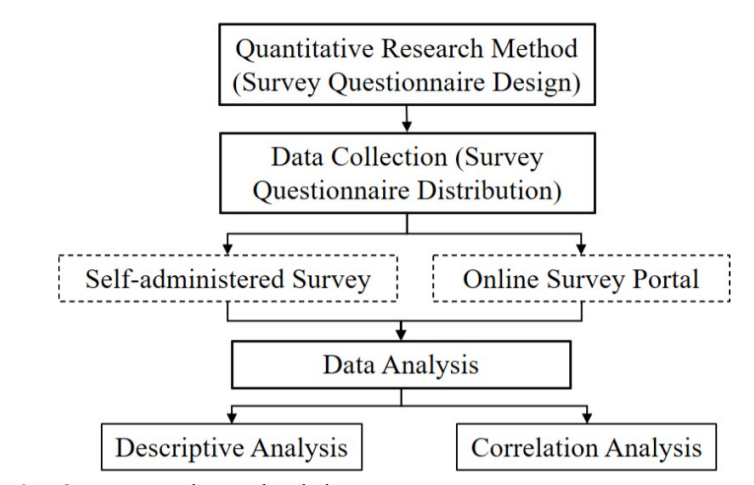

Fig. 2. Research methodology.

\subsection{Quantitative research method}

A qualitative method was employed in conducting this study. SPSS Version 23.0 was used in this research. A 
Likert scale was used to scaling responses in survey research. Through the questionnaires, respondents have been asked to indicate the level of agreement on the 6 level agreement scale, namely " 1 = strongly disagree", "2 = disagree", "3 = slightly disagree", "4 = slightly agree", " $5=$ agree", and "6 = strongly agree". A response indicating the least favorable degree is given the least score (1), and the most favorable is given the highest score (6). By combining both positive and negative items, respondents are forced to consider the question and provide a more accurate response which would reduce potential biases. Acquiescent bias occurs when participants tend to agree with all the questions in the survey. On a 6-point scale, the participants would have answered all with 5's and 6's. Extreme response bias is when the participants provide mostly high or all low ratings. On a 6-point scale, all the answered rate as 6 or 1. By alternating positive and negative items, the extreme serial responder might be reduced [16]. When a reverse-scored item, 1's is turned into 6's, 2's is turned into 5 's, 3 's is turned into 4 's, 4 's is turned into 3 's 5 's is turned into 2's, and 6's is turned into 1's. Below is a simple mathematical formula to calculate for reversescore items:

$$
\text { Reverse Score }(x)=\operatorname{Max}(x)+1-x
$$

\subsection{Data collection (survey questionnaire distribution)}

Data collection for this study is done by employing a self-administered survey method and using the online survey portal https://docs.google.com ("Google Docs"). The survey period was carried out in April 2017 for approximately a month. Survey questionnaires were distributed to 200 executives and 200 non-executives in the GLC Distribution Network Department. However, by the end of the survey period, 257 responses were collected, which equals $64.3 \%$ out of the total employees who participated.

\subsection{Reliability analysis of the questionnaire}

Cronbach's Alpha was used in the study to determine the reliability of the questionnaire. The widely accepted social science cut-off for the internal consistency Cronbach $\alpha$ is 0.7 or higher for a set to be considered as a scale [14]. According to [17], Cronbach's Alpha value of more than 0.60 is acceptable, and this method has been widely used in previous research. The guide to interpreting Cronbach's Alpha for dichotomous questions is tabulated in Table 1.

Table 1. Cronbach's Alpha interpretations.

\begin{tabular}{|c|c|}
\hline Cronbach's Alpha & Reliability \\
\hline$\alpha \geq 0.9$ & Excellent \\
\hline $0.9>\alpha \geq 0.8$ & Good \\
\hline $0.8>\alpha \geq 0.7$ & Acceptable \\
\hline $0.7>\alpha \geq 0.6$ & Questionable \\
\hline $0.6>\alpha \geq 0.5$ & Poor \\
\hline $0.5>\alpha$ & Unacceptable \\
\hline
\end{tabular}

\subsection{Validity of the instrument}

Validity is used to check whether the instrument is measuring the right things that are supposed to measure [18]. Content validity analysis includes any validity approaches that emphasize the test content. This evaluation aims to measure the independent variables and the dependent variable. Furthermore, the analysis of how the statements is built was also carried out. In this analysis, it is found that each statement is free from double-barrelled, ambiguous, recall-dependent, leading, loaded, and socially desirable. The questions are established to keep the questions straightforward, compact, and easy to understand. All the statements in the questionnaire are relevant and valid.

\section{Data analysis}

\subsection{Descriptive analysis}

Descriptive statistics were used to provide useful information on the research focus and describe the basic features of the data. Mean analysis was one of the descriptive statistical methods employed by using SPSS in this study. The suggested scale model by [19] is used to interpret the mean score, as shown in Table 2 below:

Table 2. Mean score interpretation.

\begin{tabular}{|c|c|}
\hline Mean Score & Interpretation \\
\hline $1.00-1.80$ & Strongly Disagree \\
\hline $1.81-2.60$ & Disagree \\
\hline $2.61-3.20$ & Slightly Disagree \\
\hline $3.21-4.20$ & Slightly Agree \\
\hline $4.21-5.20$ & Agree \\
\hline $5.21-6.00$ & Strongly Agree \\
\hline
\end{tabular}

\subsection{Correlation analysis}

Correlation analysis was used to determine the relationship between quantifiable variables to determine the relationship between variables. Correlation coefficients range from- 1.00 to +1.00 , with -1.00 indicating a perfect negative correlation, while +1.00 indicates a perfect positive correlation. A value of 0 indicates no correlation at all. A positive correlation coefficient indicates that there is a positive linear relationship between the variables: as one variable increases the value, so does the other. A negative value indicates a negative linear relationship between variables: as one variable increases the value, the other variable decreases the value [20]. The $r$ values present the strength of a relationship, while the p-value indicates whether there is a significant correlation between variables or not. [21] suggested that an absolute value of $r$ of 0.1 is classified as small, an absolute value of 0.3 is classified as medium, and 0.5 is classified as significant. The summary of the strength of the relationship between the two variables is tabulated in Table 3 . 
Table 3. Strength of the correlation.

\begin{tabular}{|c|c|}
\hline Correlation, $\boldsymbol{r}$ & Strength of Relationship \\
\hline $\pm .50-1.00$ & Strong relationship \\
\hline $\pm .30- \pm .49$ & Moderate relationship \\
\hline $\pm .10- \pm .29$ & Weak relationship \\
\hline
\end{tabular}

\section{Results}

\subsection{Reliability analysis of the questionnaire}

In reliability analysis, the fundamental rule is that the higher the value of Cronbach's Alpha, the better is the reliability of the data to analyze. Results of the Cronbach's Alpha value for each variable are recorded as below:

Table 4. Reliability analysis.

\begin{tabular}{|l|c|c|}
\hline \multicolumn{1}{|c|}{ Variable Subject } & $\begin{array}{c}\text { No. of } \\
\text { Item }\end{array}$ & $\begin{array}{c}\text { Cronbach's } \\
\text { Alpha }\end{array}$ \\
\hline $\begin{array}{l}\text { Management commitment } \\
\text { to safety }\end{array}$ & 5 & 0.790 \\
\hline
\end{tabular}

\begin{tabular}{|l|c|c|}
\hline $\begin{array}{l}\text { Availability of safety rules } \\
\text { and procedures }\end{array}$ & 5 & 0.816 \\
\hline Communication on safety & 5 & 0.850 \\
\hline $\begin{array}{l}\text { Effectiveness of safety } \\
\text { training }\end{array}$ & 5 & 0.760 \\
\hline $\begin{array}{l}\text { Acquisition of safety } \\
\text { knowledge }\end{array}$ & 5 & 0.877 \\
\hline $\begin{array}{l}\text { Compliance with safety } \\
\text { culture }\end{array}$ & 9 & 0.903 \\
\hline
\end{tabular}

Table 4 shows the reliability analysis of the questionnaire. The Cronbach's Alpha value obtained ranged between 0.760 and 0.903 . Therefore, the reliability of the questionnaire is accepted and can be used for further analyses throughout the research.

\subsection{Descriptive analysis}

Based on the interpretation defined in Table 5, it can be interpreted that the respondents mostly answer with "agree" since the range of mean is between 4.4047 to 5.0484. The average value of the mean for all the variables is 4.6239 .

Table 5. Mean analysis.

\begin{tabular}{|l|c|c|c|c|}
\hline \multicolumn{1}{|c|}{ Variables } & N & Mean & Std. Deviation & Mean Scale Interpretation \\
\hline Management Commitment & 257 & 4.4047 & 0.78141 & Agree \\
\hline Safety Rules \& Procedures & 257 & 4.5518 & 0.71053 & Agree \\
\hline Safety Communication & 257 & 4.5401 & 0.82632 & Agree \\
\hline Safety Training & 257 & 4.4062 & 0.74496 & Agree \\
\hline Safety Knowledge & 257 & 4.7922 & 0.75079 & Agree \\
\hline Safety Compliance & 257 & 5.0484 & 0.59759 & Agree \\
\hline Overall & 257 & 4.6239 & 0.56852 & Agree \\
\hline
\end{tabular}

*Note: Based on the Likert scale from 1 (Strongly Disagree) to 6 (Strongly Agree)

The highest mean between all the independent variables towards the compliance of safety culture in the GLC is the acquisition of safety knowledge with 4.7922 while the lowest mean is management commitment towards safety with 4.4047 .

A normality test is vital for data analysis. It is employed to determine whether sample data of the questionnaires have been drawn from a normally distributed population. SPSS statistical tests, such as the T-test and the one-way and two-way ANOVA, require a customarily distributed sample population. The distribution is measured by studying its Skewness and Kurtosis. Generally, Skewness determines the relative size of the two tails whether the data are symmetric distribution while Kurtosis is a measure of the heaviness of the tails of a distribution. According to [22], data normality means that the distribution of the data is normally distributed with mean $=0$, standard deviation $=1$, and asymmetric bell-shaped curve. [22] stated that the Skewness value should be within the range \pm 1 for normal distribution and the Kurtosis value should be within range \pm 3 for standard distribution measure while values exceeding five indicates data are non-normally distributed [23]. According to [24] posit that the acceptable range for Skewness and Kurtosis is between -1 and 1 . However, values between \pm 2 are in many cases are acceptable [25]. Table 6 below shows the descriptive statistics data which are used to describe the general overview and basic features of the data collected in this study. Based on the result, it can be concluded that the data distribution is normal.

Table 6. Descriptive statistics.

\begin{tabular}{|l|c|c|c|c|c|c|c|c|c|}
\hline \multirow{4}{*}{} & $\mathbf{N}$ & Min. & Max. & Mean & Std. Deviation & \multicolumn{2}{|c|}{ Skewness } & \multicolumn{2}{c|}{ Kurtosis } \\
\cline { 2 - 10 } & Statistic & Statistic & Statistic & Statistic & Statistic & Statistic & $\begin{array}{c}\text { Std. } \\
\text { Error }\end{array}$ & Statistic & $\begin{array}{c}\text { Std. } \\
\text { Error }\end{array}$ \\
\hline Management Commitment & 257 & 2.20 & 6.00 & 4.4047 & .78141 & -.245 & .152 & -.490 & .303 \\
\hline Safety Rules \& Procedures & 257 & 2.40 & 6.00 & 4.5518 & .71053 & -.114 & .152 & -.098 & .303 \\
\hline Safety Communication & 257 & 1.80 & 6.00 & 4.5401 & .82632 & -.308 & .152 & -.205 & .303 \\
\hline Safety Training & 257 & 2.60 & 6.00 & 4.4062 & .74496 & .019 & .152 & -.435 & .303 \\
\hline Safety Knowledge & 257 & 2.00 & 6.00 & 4.7922 & .75079 & -.737 & .152 & 1.376 & .303 \\
\hline Safety Compliance & 257 & 3.33 & 6.00 & 5.0484 & .59759 & -.248 & .152 & -.438 & .303 \\
\hline Valid N (listwise) & 257 & & & & & & & & \\
\hline
\end{tabular}




\subsection{Correlation analysis}

Pearson correlation test has been conducted to measure the existence (given by a p-value) and strength (given by the coefficient $r$ between $(-1$ and +1$)$ of a linear relationship between two variables. If the outcome is significant, we conclude that a correlation exists between the variables. The results of the correlation are tabulated as per Table 7 below.

Table 7. Correlation results.

\begin{tabular}{|c|c|c|c|c|c|c|c|}
\hline & & \begin{tabular}{|c|} 
Safety \\
Compliance
\end{tabular} & $\begin{array}{l}\text { Management } \\
\text { Commitment }\end{array}$ & $\begin{array}{c}\text { Safety Rules } \\
\& \\
\text { Procedures } \\
\end{array}$ & $\begin{array}{c}\text { Safety } \\
\text { Communication }\end{array}$ & $\begin{array}{c}\text { Safety } \\
\text { Training }\end{array}$ & $\begin{array}{c}\text { Safety } \\
\text { Knowledge }\end{array}$ \\
\hline \multirow{3}{*}{$\begin{array}{l}\text { Safety } \\
\text { Compliance }\end{array}$} & $\begin{array}{l}\text { Pearson } \\
\text { Correlation }\end{array}$ & 1 & $.298^{* *}$ & $.329^{* *}$ & $.382^{* * *}$ & $.380^{* * *}$ & $.454^{* *}$ \\
\hline & Sig. (2-tailed) & & .000 & .000 & .000 & .000 & .000 \\
\hline & $\mathrm{N}$ & 257 & 257 & 257 & 257 & 257 & 257 \\
\hline \multirow{3}{*}{$\begin{array}{l}\text { Management } \\
\text { Commitment }\end{array}$} & $\begin{array}{l}\text { Pearson } \\
\text { Correlation }\end{array}$ & $.298^{* *}$ & 1 & $.663^{* *}$ & $.668^{* *}$ & $.524^{* *}$ & $.317^{* *}$ \\
\hline & Sig. (2-tailed) & .000 & & .000 & .000 & .000 & .000 \\
\hline & $\mathrm{N}$ & 257 & 257 & 257 & 257 & 257 & 257 \\
\hline \multirow{3}{*}{$\begin{array}{l}\text { Safety Rules \& } \\
\text { Procedures }\end{array}$} & $\begin{array}{l}\text { Pearson } \\
\text { Correlation }\end{array}$ & $.329^{* * *}$ & $.663^{* *}$ & 1 & $.727^{* *}$ & $.688^{* *}$ & $.518^{* *}$ \\
\hline & Sig. (2-tailed) & .000 & .000 & & .000 & .000 & .000 \\
\hline & $\mathrm{N}$ & 257 & 257 & 257 & 257 & 257 & 257 \\
\hline \multirow{3}{*}{$\begin{array}{l}\text { Safety } \\
\text { Communication }\end{array}$} & $\begin{array}{l}\text { Pearson } \\
\text { Correlation }\end{array}$ & $.382^{* *}$ & $.668^{* *}$ & $.727^{* *}$ & 1 & $.672^{* *}$ & $.452^{* *}$ \\
\hline & Sig. (2-tailed) & .000 & .000 & .000 & & .000 & .000 \\
\hline & $\mathrm{N}$ & 257 & 257 & 257 & 257 & 257 & 257 \\
\hline \multirow{3}{*}{$\begin{array}{l}\text { Safety } \\
\text { Training }\end{array}$} & $\begin{array}{l}\text { Pearson } \\
\text { Correlation }\end{array}$ & $.380^{* *}$ & $.524^{* *}$ & $.688^{* *}$ & $.672^{* *}$ & 1 & $.517^{* *}$ \\
\hline & Sig. (2-tailed) & .000 & .000 & .000 & .000 & & .000 \\
\hline & $\mathrm{N}$ & 257 & 257 & 257 & 257 & 257 & 257 \\
\hline \multirow{3}{*}{$\begin{array}{l}\text { Safety } \\
\text { Knowledge }\end{array}$} & $\begin{array}{l}\text { Pearson } \\
\text { Correlation }\end{array}$ & $.454^{* * *}$ & $.317^{* *}$ & $.518^{* *}$ & $.452^{* *}$ & $.517^{* *}$ & 1 \\
\hline & Sig. (2-tailed) & .000 & .000 & .000 & .000 & .000 & \\
\hline & $\mathrm{N}$ & 257 & 257 & 257 & 257 & 257 & 257 \\
\hline
\end{tabular}

**. Correlation is significant at the 0.01 level (2-tailed).

Table 7 generally, shows that all five independent variables namely; management commitment towards safety, availability of safety rules and procedures, communication on safety, the effectiveness of safety training, and acquisition of safety knowledge are significantly correlated to the dependent variable (compliance of safety culture). For this study, five (5) hypotheses for correlation were tested.

Table 4 shows the reliability analysis of the questionnaire. The Cronbach's Alpha value obtained ranged between 0.760 and 0.903 . Therefore, the reliability of the questionnaire is accepted and can be used for further analyses throughout the research.

i. H1: There is a significant relationship between the management commitment towards safety and compliance of safety culture in the organization. Based on Table 7, shows that there is a significant positive relationship between the variable management commitment towards safety and employee's compliance towards safety culture, where $r=0.298, n=257, p<0.00$. Thus, from the correlation, it can be concluded that hypothesis $\mathrm{H} 1$ is accepted.

ii. H2: There is a significant relationship between the availability of safety rules and procedures and compliance with safety culture in the organization. Based on Table 7, shows that there is a significant positive relationship between the variable availability of safety rules and procedures and employee's compliance towards safety culture, where $r=0.329, n=257, p<0.00$. Thus, from the correlation, it can be concluded that hypothesis $\mathrm{H} 2$ is accepted.

iii. H3: There is a significant relationship between safety communication and feedback and compliance of safety culture in the organization. Based on Table 7, shows that there is a significant positive relationship between the variable communication on safety and employee's compliance towards safety culture, where $\mathrm{r}=$ $0.382, \mathrm{n}=257, \mathrm{p}<0.00$. Thus, from the correlation, it can be concluded that hypothesis H3 is accepted.

iv. There is a significant relationship between the effectiveness of safety training and compliance of safety culture in the organization. Based on Table 7 , shows that there is a positive relationship between the variable effectiveness of safety training and employee's compliance towards safety culture, where $\mathrm{r}=0.380, \mathrm{n}=257, \mathrm{p}<0.00$. Thus, from the correlation, it can be concluded that hypothesis H4 is accepted.

v. There is a significant relationship between the acquisition of safety knowledge and compliance with safety culture in the organization. Based on Table 7, shows that there is a positive relationship 
between the variable acquisition of safety knowledge and employee's compliance towards safety culture, where $\mathrm{r}=0.454, \mathrm{n}=257, \mathrm{p}<0.000$. Thus, from the correlation, it can be concluded that hypothesis H5 is accepted.

Table 8. Interpretation of correlation scale.

\begin{tabular}{|c|c|c|}
\hline Variable Subject & Correlation, $\boldsymbol{r}$ & $\begin{array}{c}\text { Strength of } \\
\text { Relationship }\end{array}$ \\
\hline $\begin{array}{c}\text { Management } \\
\text { commitment to safety }\end{array}$ & 0.298 & $\begin{array}{c}\text { Weak } \\
\text { relationship }\end{array}$ \\
\hline $\begin{array}{c}\text { Availability of safety } \\
\text { rules and procedures }\end{array}$ & 0.329 & $\begin{array}{c}\text { Moderate } \\
\text { relationship }\end{array}$ \\
\hline $\begin{array}{c}\text { Communication on } \\
\text { safety }\end{array}$ & 0.382 & $\begin{array}{c}\text { Moderate } \\
\text { relationship }\end{array}$ \\
\hline $\begin{array}{c}\text { Effectiveness of } \\
\text { safety training }\end{array}$ & 0.380 & $\begin{array}{c}\text { Moderate } \\
\text { relationship }\end{array}$ \\
\hline $\begin{array}{c}\text { Acquisition of safety } \\
\text { knowledge }\end{array}$ & 0.454 & $\begin{array}{c}\text { Moderate } \\
\text { relationship }\end{array}$ \\
\hline
\end{tabular}

From Table 8. the correlation, $r$ results for independent variable management commitment towards safety value of '0.298' shows a weak relationship between the compliance towards safety culture practices in the GLC. Even though the relationship is weak, management commitment still has a relationship with the dependent variables and was positively correlated with the compliance of safety culture. The correlation results for other independent variables (availability of safety rules and procedures, communication on safety, the effectiveness of safety training, and acquisition of safety knowledge) statistically display a moderate relationship between the compliance of safety culture practices in the GLC. The correlation, $r$ results are between '0.329' to '0.454' shows that the independent variables were positively correlated with dependent variables. This result reveals statistically that any positive change in all five independent variables (management commitment towards safety, availability of safety rules and procedures, communication on safety, the effectiveness of safety training, and acquisition of safety knowledge) lead to increase the employees' compliance towards implementing safety culture in the organizational.

\section{Discussion}

\subsection{Management commitment related to safety}

Based on the descriptive studies, it is shown that the average value of the mean for variable management commitment is 4.4047 . The majority of the workers were agreed that the management was committed to developing a safety culture in the organization. This result indicates that there is still room for improvement for management commitments practices towards safety in the GLC.

Based on the correlation analysis, management commitment is the only independent variable that resulted in a weak relationship as compared to the other four (4) independent variables. It also did not contribute towards safety culture since the enforcements were not strictly carried out by the top management such as management by walk about (MBWA) and safety quality enforcement (SQE). Apart from that, the roles of the senior management and supervisor at the site were very minimal to assure the safe performance practiced by workers.

A successful safety management commitment requires a delicate balance of safety cultural acceptance, best practices in the work processes, and the right degree of system and technology support. The safety performance improves further if the focus is in the right direction and the implementation of the strategy. Management commitment will encourage both management and employees to create a workplace that is as safe as possible. The involvement of the top management will lead to better safety performance by demonstrating their commitment to safety.

\subsection{Availability of safety rules and procedures}

Based on the descriptive studies, it is shown that the average value of the mean for variable management commitment is 4.5518 . The majority of workers were agreed that the safety rules and procedures are available at the company and very useful in developing safety cultures in the organization. This result indicates that there are still rooms for improvement for safety rules and procedures to influence safety culture in the organization.

The result from the correlation analysis shows that there is a moderate and positive relationship between the availability of safety rules and procedures towards compliance with safety culture. Safety rules and procedures are vital components of the internal risk control system to ensure customers, employees and owners do not get injured during business operations. It can help to prevent accidents from happening in the business environment and allow employees to work quicker and improve the level of productivity.

\subsection{Safety communication and feedback}

Based on the descriptive studies, it is shown that the average value of the mean for variable management commitment is 4.5401 . From the results, it appears that all respondents were agreed that safety communication and feedback are important in creating a safety culture in the organization.

From the correlation analysis, there is a moderate and positive relationship between the availability of safety communication and feedback towards safety with compliance of safety culture. The more active, the organizational communication related to safety, the more improved the compliance of safety culture and safety performance.

\subsection{Effectiveness of safety training}

Based on the descriptive studies, it is shown that the average value of mean for variable safety training is 4.4062. The workers were agreed that the safety training provided by the company was effectively developing a safety culture among the workers. However, there is still 
room for improvement in the effectiveness of safety training implementation in the GLC.

The findings from correlation analysis revealed that there is a moderate and positive relationship between the effectiveness of safety training towards safety with compliance of safety culture.

A practical safety training is absolutely a worthy investment considering the loss in staff productivity (lost time injury), property damage, and cost arising from an accident, which could have been prevented. Many injuries and property damage can be prevented with the sharing of a lesson learned for accidents that happened by implementing practical safety training and refresher courses every year. Safety training helps employees to give safety its due importance with a useful job analysis and risk hierarchy control techniques. Safety training also helps the employees to choose the right protective clothing and equipment (PPE) to safeguard themselves against any hazardous job task and activity.

\subsection{Acquisition of safety knowledge}

Based on the descriptive studies, it is shown that the average value of mean for variable safety training is 4.7922, which is also the highest mean among all the independent variables. From the result, it can be concluded that most workers were agreed that the acquisition of safety knowledge is vital in developing compliance towards a safety culture.

From the correlation analysis, it can be seen that there is a positive relationship between the acquisition of safety knowledge towards safety with compliance of safety culture. Safety knowledge recorded the highest correlation, $r$ compared to the other four (4) independent variables and it is the only factor that has significance and contributes to the dependent variable which is the compliance of safety culture.

Awareness of safety knowledge stimulates productivity and produces better work outcomes. The employee with good safety knowledge increases their work productivity and provide them with a better understanding of manoeuvring through the related safety issues in their daily task and activity. With the management's support and persistence, changes in the organization's safety culture have taken place in selflearning initiative and knowledge communication. The familiarity with this safety knowledge acquisition helps the employee practice and apply for the safety course during the employee's working hours. Due to that, they would need to learn the right processes, that refer with regards to the safe manner in which how the task is supposed to be carried out with a safe manner, to refresh themselves with the safety rules and procedures, and other purposes related to the nature of their job responsibilities. This knowledge has proven to be meaningful; ultimately, the employees acquire knowledge to take necessary precautions when delivering their daily tasks, and they know how to decrease the risk of accidents in the workplace.

\section{Conclusion}

This research is focused on five factors; the management commitments towards safety, availability of safety rules and procedures, safety communication and feedback, the effectiveness of safety training, and the acquisition of safety knowledge that contributes to compliance of safety culture in the government-linked companies (GLC), by exploring various dimensions by which converge into achieving organizational safety performance outcomes. The importance of safety performance in the Malaysia GLC is to ensure the employees have the right safety culture, a safe working environment, and comply with safety rules and procedures. The findings provide good evidence and support for researchers to explore the effect of the attributes such as safety management, rules and procedures, communication and feedback, and knowledge with regards to employees' safety compliance towards a better safety culture in the organization.

Theoretically, the acquisition of safety knowledge is a very crucial element in the safety management system since it contributes $24.2 \%$ towards compliance with safety culture in the GLC. Therefore, it can be concluded that management practices should continue to focus on how to ensure that the employees are equipped with all the required knowledge. The GLC needs to revaluate its existing and future safety management strategies as well. Apart from that, this study also provides an empirical review on which components of safety management practices have a better relationship with the organizational safety culture.

Safety performance is very vital to achieve GLC goals, which are geographical expansion. The GLC aims to excel in all its business areas domestically as well as globally, and it can be achieved through an excellent safety performance which reflects a high competency in managing the energy industry. A good result of safety performance gives a reasonable perception by the public, government, stakeholders, business partners, and competitors. It's the safety culture within the organization that drives towards achieving these goals.

The contribution of the findings of this study may provide the improvement of existing safety management practices in the GLC. It facilitates the organization in evaluating the importance of safety management on their overall productivity performance in the company by creating a good safety culture. Based on the study, there is a positive correlation between management commitments towards safety, availability of safety rules and procedures, safety communication and feedback, the effectiveness of safety training, and acquisition of safety knowledge with regards to employees' safety compliance towards a better safety culture in the organization. To conclude this study, the findings and result analysis indicate that the level of compliance with safety culture is the fundamental approach to enhance overall safety performance in the organization.

The research presented in this paper is funded by Tenaga Nasional Berhad (TNB) through a post-graduate university scholarship at UNITEN and UNITEN R \& D Sdn. Bhd. under 
URND Seeding Fund (U-TE-RD-19-19). The authors would like to thanks Universiti Tenaga Nasional (UNITEN) and UNITEN R \& D Sdn. Bhd. for the opportunity and sponsorship in completing this study.

\section{References}

1. A. Cohen, Safety Research 9, 168-178 (1977)

2. M. Smith, H. Cohen, A. Cohen, R. Cleveland, J. of Safety Research 10, 5-15 (1978)

3. R. Simonds, Y. Shafai-Sahrai, J. of Safety Research 9,120-127 (1997)

4. M.S. Christian, J. C. Bradley, J. C. Wallace, M. J. Burke, J. of Applied Psy. 94, 5:1103-1127 (2009)

5. D. Goetsch, Occupational safety and health for technologists, Engineers, and Managers. Seventh Edition (Prentice-Hall, USA, 2011)

6. S. Hood, Developing operating procedures: 9 steps to success (Accident Prevention, 1994)

7. N.H. Zakaria, N. Mansor, Z. Abdullah, Business \& Management Review 2, 5:75-88 (2012)

8. H. Y. Chong, S. L. Thuan, Inter. J.of Occupational Safety \&Ergonomic 20, 3:503-513 (2014)

9. S. Brisk, S. Workplace accidents: How to avoid them and what to do when they happen, URL: Business.com (2016)

10. J. Williams, Improving safety communication skills: becoming an empathic communicator (The American Society of Safety Session 716, Blacksburg, Virginia, 2006)

11. M. Hallowell, J. Gambatese, J. Construction Safety Risk Mitigation. J. Const. Eng. Manage 135, 12:1316-1323 (2009)

12. J. Wintle, P. Moore, N. Henry, S. Smalley, G. Amphlett, Plant ageing, management of equipment containing hazardous fluids or pressure (Health and Safety Executive, research report RR509, Norwich, 2006)

13. Z. Hassan, C. Subramaniam, Md. Lazim Mohd. Zin, F. Mohd. Shamsudin, S. Ramalu, Academy of Entrepreneurship J 25, 2S (2019)

14. M. Vinodkumar, M. Bhasi, Accident Analysis \& Prevention, 42 (2010)

15. S. Zakaria, S. Inter. Education Studies 9, 5 (2016)

16. J. Sauro, J. Lewis, When designing usability questionnaires, does it hurt to be positive?, in CHI, May 7-12, 2011, Vancouver, BC, Canada (2011)

17. D. Cooper, P. Schindler, Business research methods (12 ed.) (Irwin Professional, Boston, Massachusetts, USA, 2013)

18. A. Bryman, D. Cramer, Quantitative data analysis with SPSS 12 and 13. a guide for social scientists (Taylor \& Francis e-Library, 2005)

19. K. Moidunny, The effectiveness of the National Professional Qualification for Educational Leaders (NPQEL) (The National University of Malaysia, Malaysia, 2009)
20. J. Cortina, J. of Applied Psy. 78, 98-104 (1993)

21. J. Cohen, Statistical power analysis (2nd ed.) (Erlbaum, Hillsdale NJ, 1998)

22. B. Byrne, B. Structural equation modeling with AMOS: basic concepts, applications, and programming (Routledge, New York, 2010)

23. P. Bentler, EQS 6 Structural equations program manual (CA: Multivariate Software, Inc., Encino, 2006)

24. C. Dwork, V. Feldman, M. Hardt, T. Pitassi, O. Reingold, A. Roth, Preserving statistical validity in adaptive data analysis, in Proceedings of the Forty-Seventh Annual ACM on Symposium on Theory of Computing, Portland, Oregon, USA (2015)

25. D. George, P. Malery, SPSS for Windows step by step. A simple guide and reference fourth edition (11.0 update) (La Sierra University, California, 2005)

26. A. Ek, Safety culture in sea and aviation transport, Doctoral thesis 